\title{
Kappa Light Chain Measurement
}

National Cancer Institute

\section{Source}

National Cancer Institute. Kappa Light Chain Measurement. NCI Thesaurus. Code C147379.

The determination of the amount of kappa light chain present in a sample. 